Original Article

\title{
Phytochemical screening and antimicrobial activities studies of Acacia nilotica fruit cover
}

\author{
Abdelhamed A. Abdalla, Mujahed I. Mustafa*, and Abdelrafie M. Makhawi \\ Department of Biotechnology, University of Bahri, Khartoum, Sudan. \\ *Corresponding author: Mujahed I. Mustafa; mujahedimustafa@gmail.com
}

\begin{abstract}
This study was carried out in Khartoum state, during November, 2019. Acacia nilotica was chosen for this study because of its using traditionally in treatment of many diseases. The Phytochemical constitutions of A. nilotica were investigated with aim to identify the antimicrobial effects of this plant. The dried fruit cover of Acacia nilotica was extracted successively with petroleum-ether, chloroform, methanol and distilled water. The phytochemical screening carried out on different extracts of Acacia nilotica fruit cover showed high amount of Glycosides, Flavonoids and Terpenoids (in all extracts) and moderate amount of Tannin in methanol and distilled water extracts, Alkaloids (acid and base) in methanol extract and Saponin in methanol and petroleum-ether extracts .The antimicrobial activity of extracts were evaluated against four standard bacteria species (gram positive bacteria; Staphylococcus aureus, Bacillus subtilis) and (gram negative bacteria; Pseudomonas aeruginosa, Escherichia coli). The plates were inoculated for sensitivity testing, minimum inhibitory concentration (MIC) was measured. The results of antimicrobial investigation show that the distilled water and methanolic extracts inhibited the growth of all microorganisms (Specified by the zone of inhibition). The results provide promising baseline information for potential use of these crude extracts in drug development programs in the pharmaceutical industries.
\end{abstract}

Keywords: Acacia nilotica fruit cover, antimicrobial activity, crude extracts, minimum inhibitory concentration (MIC), phytochemical screening, zone of inhibition. 


\section{Introduction:}

Infectious diseases impact our quality of life and may lead to systemic and threatening diseases. Antibiotics have saved the lives of millions of people and have contributed to the major gains in life expectancy over the last century. However, the clinical efficacy of many existing antibiotics is being threatened by the emergence of multi-drug resistant (MDR) pathogens the recent appearance of strains with reduced susceptibility as well as, undesirable side effects of certain antibiotics; because of the increased microbial resistance to antibiotics, toxic and harmful effects of few common antimicrobial agents;[1] therefore, a critical needs to study the biological properties of additional medicinal plants in order to develop new antibiotics.

Medicinal plants have been a valuable source of natural active constituents that products for maintain human health and treatment of many human diseases. Over $50 \%$ of all modern clinical drugs are of natural product origin and natural products play an important role in drug development programs in the pharmaceutical industries.[2, 3]

Acacia nilotica (Babul tree) is the member of the family Mimosaceae; Acacia nilotica is multipurpose nitrogen fixing tree legume. It is widely spread in subtropical and tropical Africa from Egypt to Mauritania southwards to South Africa, and in Asia eastwards to Pakistan and India.[4] Phytochemical analysis of the aerial parts of the plant demonstrated the presence of polyphenolic compounds and flavonoids in the flowers. Tannins, volatile oils, glycosides, coumarins, carbohydrates and organic acids are reported in the fruits.[5] Babul has been reported to contain 1 arabinose, catechol, galactan, galactoaraban, galactose, N-acetyldjenkolic acid, Nacetyldjenkolic acid, sulphoxides pentosan, saponin and tannin. Seeds contain crude protein $18.6 \%$, ether extract $4.4 \%$, fiber $10.1 \%$, nitrogen-free extract $61.2 \%$, ash $5.7 \%$, silica $0.44 \%$, phosphorus $0.29 \%$ and calcium $0.90 \%$ of DM.[6, 7]

Acacia nilotica especially and other Acacia species are used in local traditional medicine by people as remedy for various disorders like cancers of (ear, eye or testicles) and indurations of liver and spleen, condylomas and excess flesh. It may also be used for colds, congestion, coughs, diarrhea, dysentery, fever, gallbladder, hemorrhage, 
hemorrhoids, leucorrhea, ophthalmia, sclerosis, smallpox and tuberculosis.[8]. Recent studies in drug discovery from medicinal plants includes a multi-layered approach relating molecular, botanical, and phytochemical techniques;[9] therefore, this present study focuses on the biochemical properties of Acacia nioltica using different solvents and on antimicrobial potential of Acacia nilotica. In this paper the antimicrobial activity of methanolic and aqueous extracts of Acacia nilotica was established against Grampositive and Gram-negative bacteria. The crude extracts were investigated against 4 strains of bacteria (Escherichia coli, Staphylococcus aureus, Bacillus subtilus and Pseudomonas aeruginosa).

\section{Materials and methods:}

Workflow demonstrates the procedure for phytochemical screening and antimicrobial activities of Acacia nilotica in figure $\mathbf{1}$.

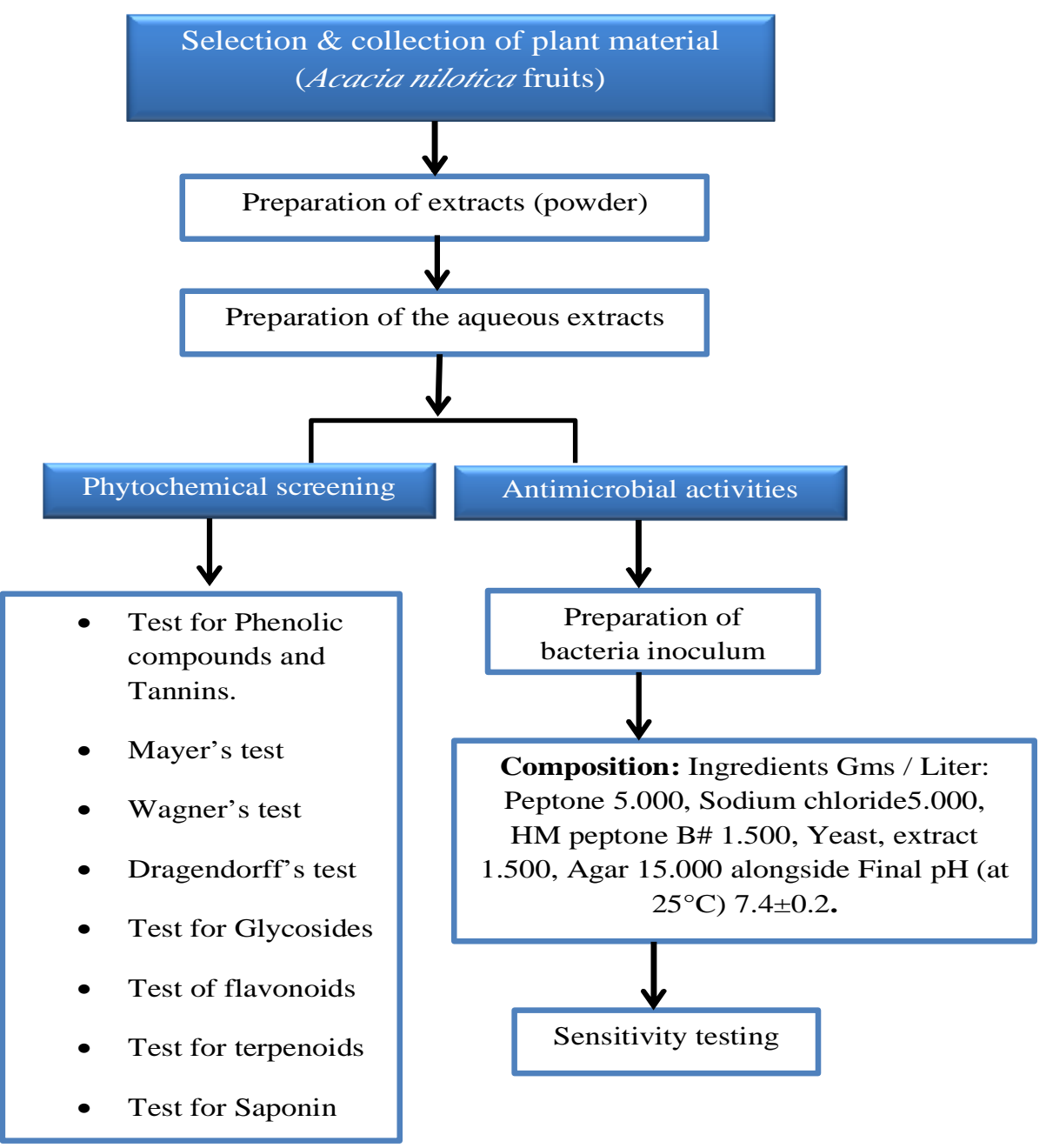




\subsection{Selection and collection of plant material:}

Five hundred grams of Acacia nilotica fruits were obtained from Souq Lybia (Omdurman, Sudan) in a clean container during November, 2019.

\subsection{Preparation of extracts:}

Extraction was carried out according to method described by Sukhdev et. al. [10] The plant sample was coarsely powdered using mortar and pestle. Coarsely sample was extracted with absolute ethanol, chloroform, and petroleum-ether using Soxhlet extractor apparatus. Extraction carried out for about five hours till the color of solvents at the last siphoning time returned colorless. Solvents were evaporated under reduced pressure using rotary evaporator apparatus. Finally extracts allowed to air in Petri dish till complete dryness and the yield percentage were calculated as followed:

Table (1): Shows weight of extract obtained / weight of plant sample X100:

\begin{tabular}{cccc}
\hline Sample & Weight of sample in gm & Weight of extract & Yield \% \\
\hline Acacia nioltica petroleum-ether extract & $100 \mathrm{~g}$ & $1.52 \mathrm{~g}$ & $1.52 \%$ \\
Acacia nioltica chloroform extract & $100 \mathrm{~g}$ & $1.72 \mathrm{~g}$ & $1.72 \%$ \\
Acacia nioltica methanol extract & $100 \mathrm{~g}$ & $45.06 \mathrm{~g}$ & $45.06 \%$ \\
\hline
\end{tabular}

\subsection{Preparation of the aqueous extracts:}

Extraction was carried out according to method described by Sukhdev et. al.[10] $40 \mathrm{~g}$ of the sample was extracted by soaking in $200 \mathrm{ml}$ hot distilled water for about four hours with continuous steering. After cooled, extract was filtered using filter paper and stored till used for the antimicrobial activity. Concentration was calculated by dried $2 \mathrm{ml}$ of the extract in a Petri dish using water as followed:

(Weight of dish with extract - empty weight) X100 / 2

Table (2): Weight of extract obtained / weight of plant sample X100:

\begin{tabular}{cccc}
\hline Sample & Weight of sample in gm. & Weight of extract & Yield \% \\
\hline Acacia nioltica aqueous extract & $40 \mathrm{~g}$ & $6.63 \mathrm{~g}$ & $6.63 \%$ \\
\hline
\end{tabular}




\subsection{Phytochemical screening:}

The standard phytochemical screening was done with few modifications described by

Farnsworth et al. Harbone and Sofowora.[11-13]

\subsubsection{Test for Phenolic compounds and Tannins (Ferric Chloride test):}

The extract $(50 \mathrm{mg})$ is dissolved in $5 \mathrm{ml}$ of distilled water. To this few drops of neutral $5 \%$ ferric chloride solution are added. A dark green color indicates the presence of phenolic compound.

\subsubsection{Mayer's test:}

To a few ml of plant sample extract, two drops of Mayer's reagent was added on the sides of test tube. Appearance of white creamy precipitate indicates the presence of alkaloids.

\subsubsection{Wagner's test:}

A few drops of Wagner's reagent are added to few $\mathrm{ml}$ of plant extract along the sides of test tube. A reddish- Brown precipitate confirms the test as positive.

\subsubsection{Dragendorff's test:}

To $2 \mathrm{mg}$ of the ethanolic extract $5 \mathrm{ml}$ of distilled water was added, 2M Hydrochloric acid was added until an acid reaction occurs. To this $1 \mathrm{ml}$ of Dragendorff's reagent was added. Formation of orange or orange red precipitate indicates the presence of alkaloids.

\subsubsection{Test for Glycosides (Borntrager's test)}

To $2 \mathrm{ml}$ of filtered hydrolyte, $3 \mathrm{ml}$ of chloroform is added and shaken, chloroform layer is separated and $10 \%$ ammonia solution is added to it. Pink color indicates presence of glycosides.

\subsubsection{Test of flavonoids:}

Three $\mathrm{ml}$ of $1 \%$ Aluminum chloride solution were added to $5 \mathrm{ml}$ of each extract. A yellow coloration was observed indicating the presence of flavonoids. 


\subsubsection{Test for terpenoids (Salkowski test):}

Five $\mathrm{ml}$ of each extract was mixed with $2 \mathrm{ml}$ of chloroform, and $3 \mathrm{ml}$ concentrated $\mathrm{H} 2 \mathrm{SO} 4$ was carefully added to form a layer. A reddish brown coloration of the interface was formed to show positive results for the presence of terpenoids.

\subsubsection{Test for Saponin:}

The extract $(50 \mathrm{mg}$ ) is diluted with distilled water and made up to $20 \mathrm{ml}$. The suspension is shaken in a graduated cylinder for 15 minutes. A two cm layer of foam indicates the presence of Saponin.

\subsection{Preparation of bacteria inoculum:}

A $24 \mathrm{~h}$ old culture of bacterial isolate was emulsified in sterile nutrient broth media.

2.6. Media Used (Nutrient Agar M001, HiMedia Laboratories, India):

\subsubsection{Intended use:}

Nutrient Agar is used as a general purpose medium for the cultivation of less fastidious microorganisms, can be enriched with blood or other biological fluids.

\subsubsection{Composition:}

Ingredients Grams/ Liter: Peptone 5.000, Sodium chloride 5.000, HM peptone B\# 1.500, Yeast, extract 1.500, Agar 15.000 alongside Final pH (at $25^{\circ} \mathrm{C}$ ) 7.4 \pm 0.2 .

\subsection{Sensitivity testing:}

The method used was the well diffusion dilution technique on Nutrient Agar plates. 0.1 $\mathrm{ml}$ of a broth culture of each organism (E. coli, Staphylococcus aureus, Bacillus subtilus and Pseudomonas aeruginosa) was spread on each plate. Wells (measuring $12 \mathrm{~mm}$ in diameter) were cut out of the Nutrient Agar under aseptic conditions using sterile blue tubes. Each well was filled with $20 \mu \mathrm{l}$ of the Acacia nilotica extract of different solvent at different concentrations $(100,50,25,12.5 \mu \mathrm{g} / \mathrm{ml})$. Plates were refrigerated for 2 hours to allow proper diffusion before incubation at $37^{\circ} \mathrm{C}$ for 24 hours. After incubation, the 
inoculated sensitivity plates were removed from the incubator and under good illumination the inhibition zones around the wells were measured. An inhibition zone measuring more than $14 \mathrm{~mm}$ was considered sensitive.[14]

\section{Results:}

\subsection{Phytochemical screening results:}

Four solvent was used in extraction methanol, chloroform, distill water and petroleumether. The extracts were found that all contain glycosides, flavonoids and terpenoids. The tannins were present in methanol and aqueous extracts. Where present in methanol extract. In addition Saponin was found in petroleum ether and methanol.

Table (3): Shows phytochemical screening results:

\begin{tabular}{ccccc}
\hline Test/ Solvent & Methanol & Petroleum ether & Chloroform & Distilled water \\
\hline Tannin ferric chloride & + & - & - & + \\
Wagner's & + & - & - & - \\
Dragendorff's & + & - & - & + \\
Mayer's & + & - & - & - \\
Wagner's & + & - & - & - \\
Dragendorff's & + & - & - & - \\
Mayer's & + & - & - & + \\
Glycosides(Borntrager's test) & + & + & + & + \\
Flavonoids & + & + & + & + \\
Terpenoids(Salkowski test) & + & + & + & - \\
Saponin & + & + & - & \\
\hline
\end{tabular}

+ means positive result; - means negative result. 


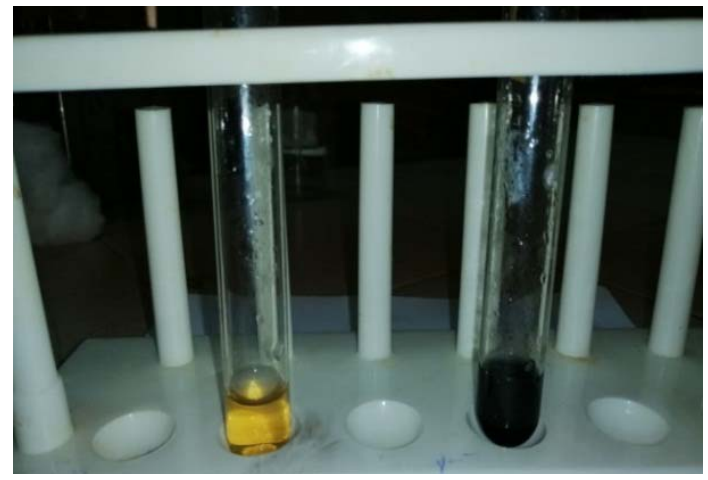

(A)

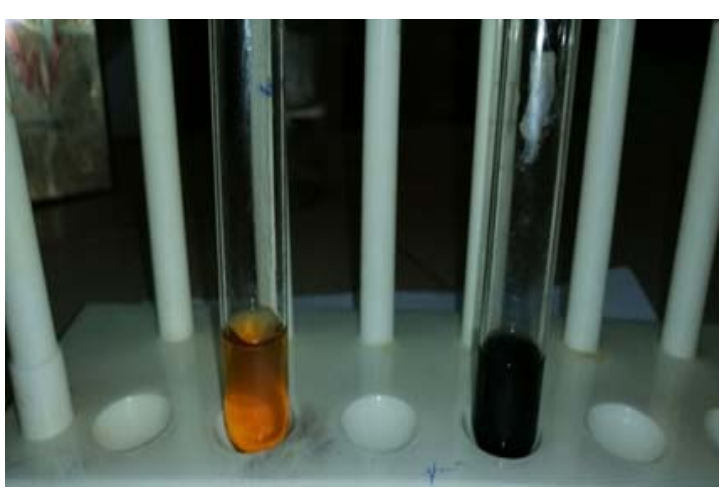

(B)

Figure (2): Tannins test of Acacia nioltica (A) is aqueous extract while (B) is methanol extract.

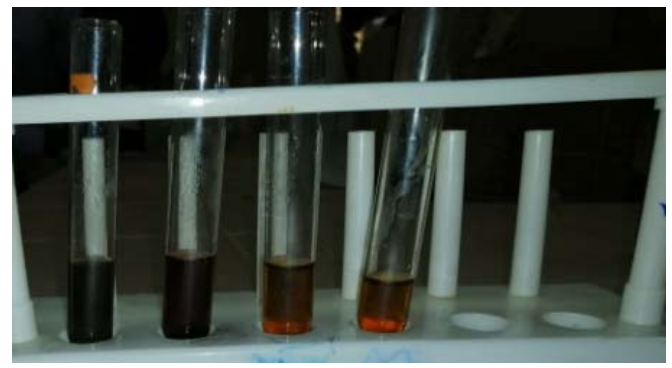

(A)

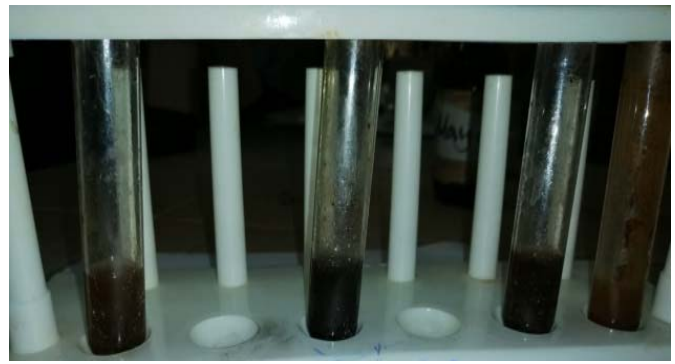

(B)

Figure (3): Alkaloids test of Acacia nioltica (A) is aqueous extract While (B) is methanol extract.

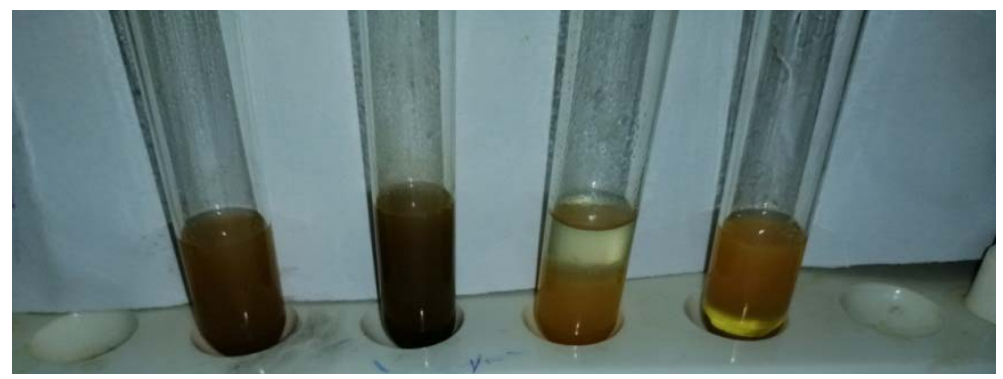

Figure (4): Glycosides test of Acacia nioltica aqueous, methanol, Petroleum ether, chloroform extract. 


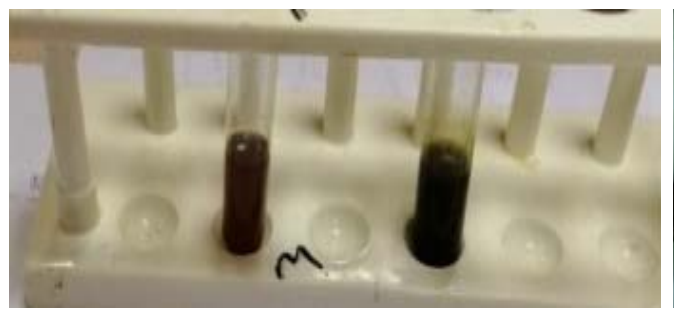

(A)

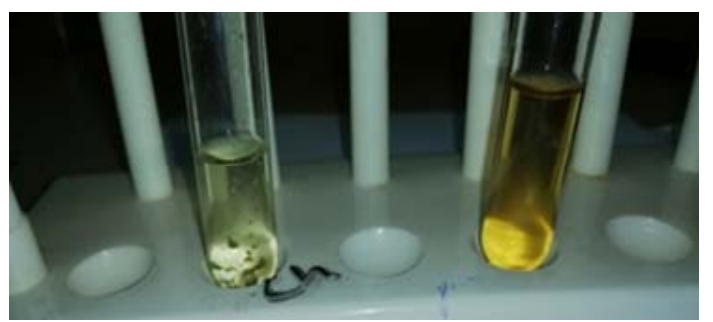

(C)

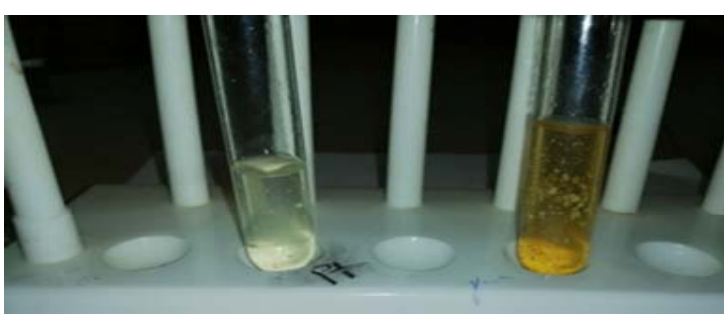

(B)

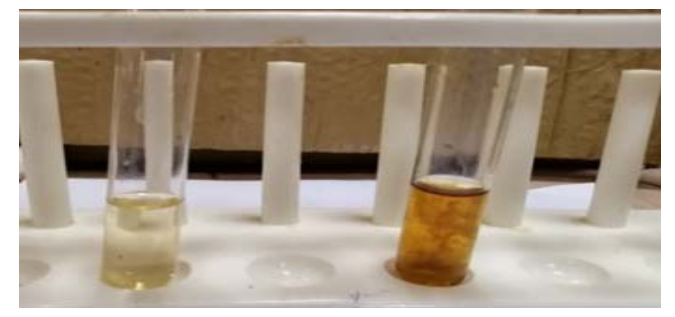

(D)

Figure (5): Flavonoid test of Acacia nioltica (A) methanol extract, (B) Petroleum ether extract, (C) chloroform extract (D) aqueous extract.

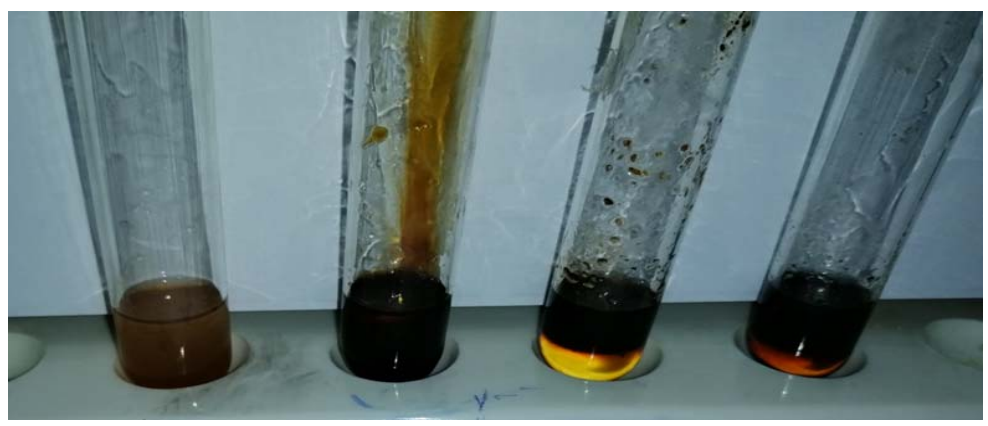

Figure (6): Terpenoids test of Acacia nioltica aqueous, methanol, Petroleum-ether and chloroform extract.
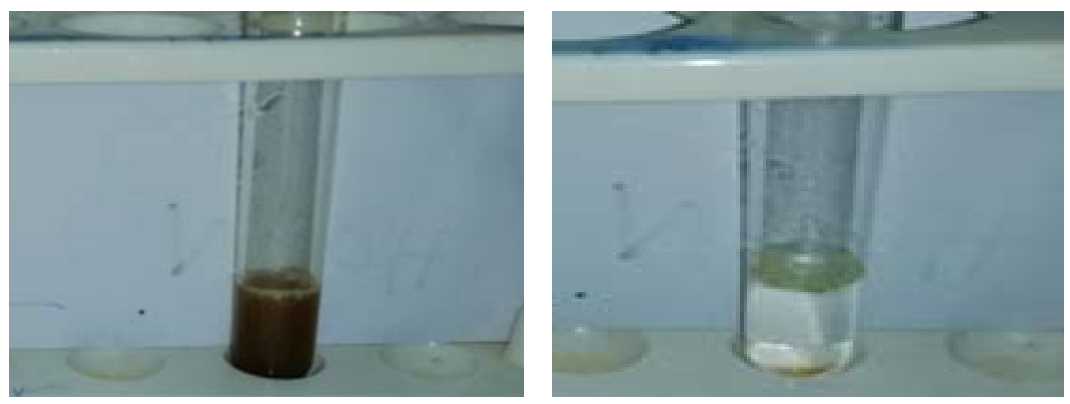

Figure (7): Saponin test of Acacia nioltica: methanol extract and petroleum-ether extract. 


\subsection{Antimicrobial activity:}

The methanolic and aqueous extract showed high inhibition zone against all tested microorganisms. Petroleum ether has one inhibition zone against Pseudomonas aeruginosa at one concentration $(100 \mathrm{mg} / \mathrm{ml})$. At same time the chloroform has no inhibition zone against all tested microorganisms.

Table (4): Shows antimicrobial test results (Zone of Inhibition in $\mathrm{mm}$ ):

\begin{tabular}{cccccc}
\hline Solvent & Concentration & S.a & P.s & B.s & E.c \\
\hline Methanol & 100 & 22 & 23 & 24 & 21 \\
& 50 & 19 & 21 & 22 & 17 \\
& 25 & 18 & 18 & 20 & 15 \\
& 12.5 & 15 & 16 & 17 & ND \\
\hline Petroleum ether & 100 & ND & 17 & ND & ND \\
& 50 & ND & ND & ND & ND \\
& 25 & ND & ND & ND & ND \\
& 12.5 & ND & ND & ND & ND \\
\hline Chloroform & 100 & ND & ND & ND & ND \\
& 50 & ND & ND & ND & ND \\
& 25 & ND & ND & ND & ND \\
& 12.5 & ND & ND & ND & ND \\
\hline Distilled water & 100 & 22 & 28 & 25 & 20 \\
& 50 & 20 & 26 & 18 & 18 \\
& 25 & 18 & 25 & 16 & 14 \\
& 12.5 & ND & 22 & ND & ND \\
\hline
\end{tabular}

S.a: Staphylococcus aurous, P.s: Pseudomonas aeruginosa, B.s: Bacillus subtilis, E.c: Escherichia coli; concentration of extracts $(100,50,25,12.5 \mathrm{mg} / \mathrm{ml})$ respectively. ND: Not determined. 
bioRxiv preprint doi: https://doi org/10.1101/2020 02 11 943456; this version posted February 12, 2020. The copyright holder for this preprint (which was not certified by peer review) is the author/funder, who has granted bioRxiv a license to display the preprint in perpetuity. It is made available under aCC-BY-NC-ND 4.0 International license.

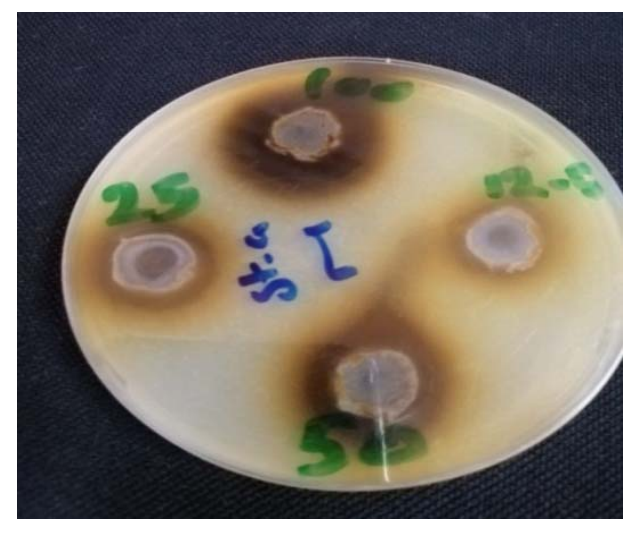

(1)

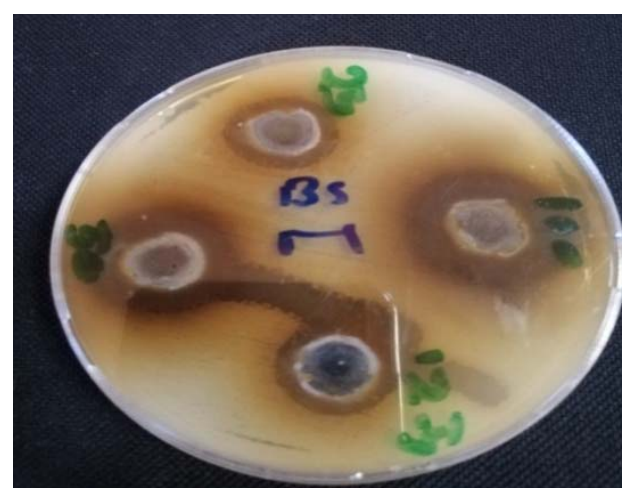

(3)

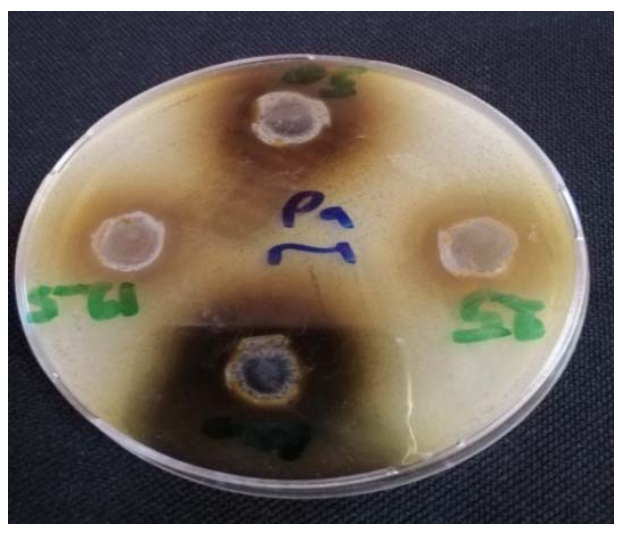

(2)

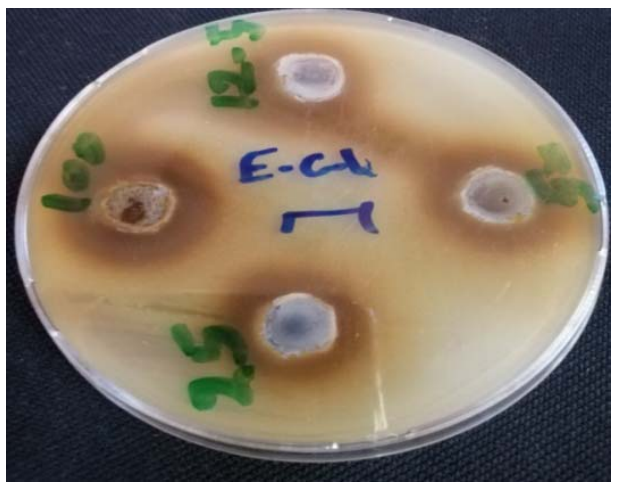

(4)

Figure (8): Antimicrobial activity of Acacia nioltica methanol extract against (1) Staphylococcus auras, (2) Pseudomonas aeruginosa, (3) Bacillus subtilus and (4) Escherichia coli. 
bioRxiv preprint doi: https://doi.org/10.1101/2020.02 11.943456; this version posted February 12, 2020. The copyright holder for this preprint (which was not certified by peer review) is the author/funder, who has granted bioRxiv a license to display the preprint in perpetuity. It is made available under aCC-BY-NC-ND 4.0 International license.

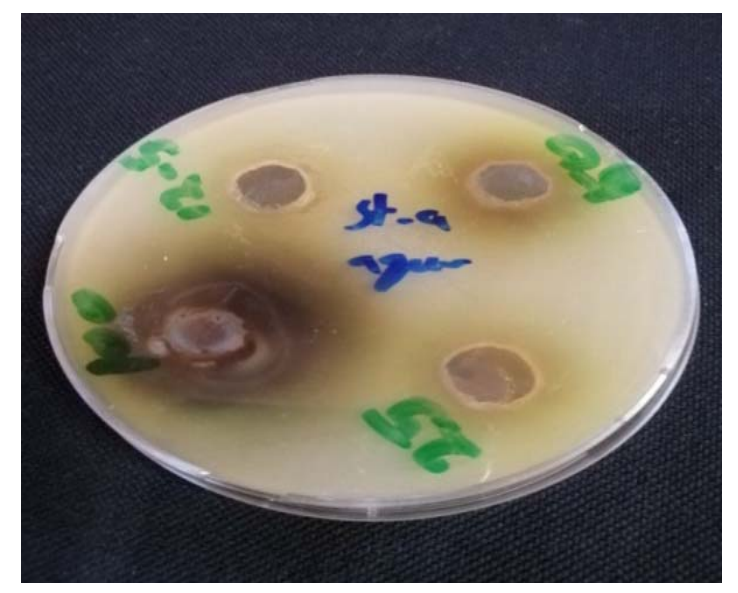

(A)

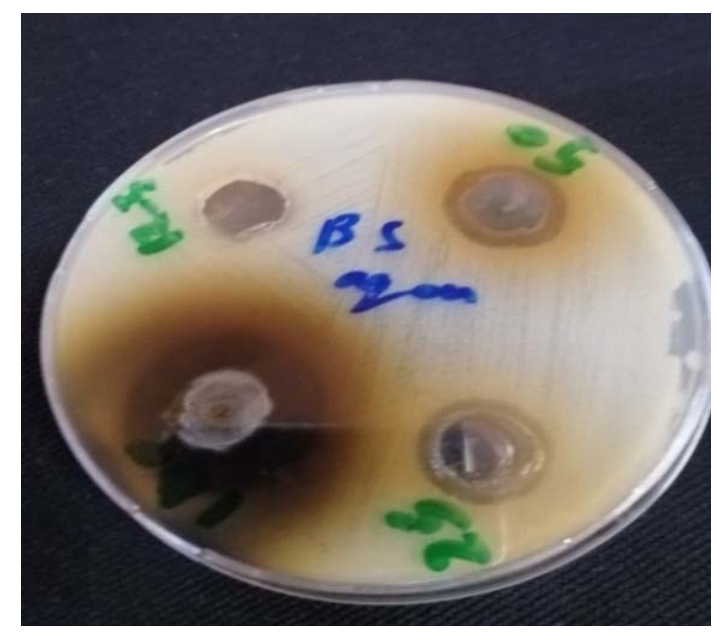

(C)

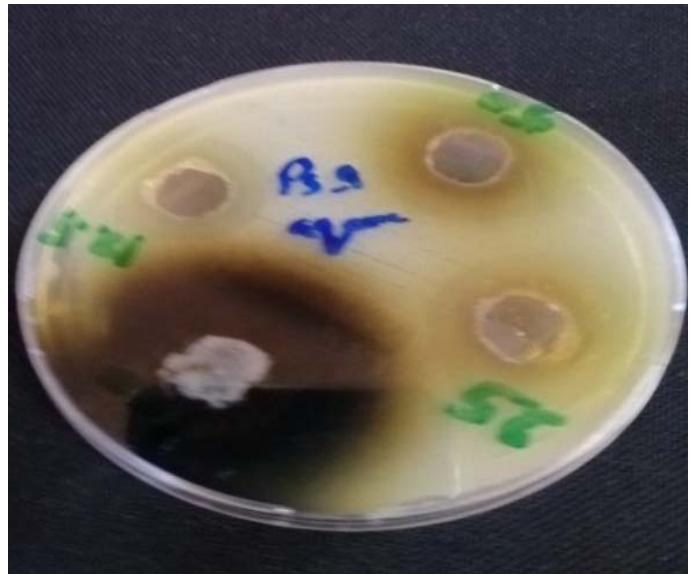

(B)

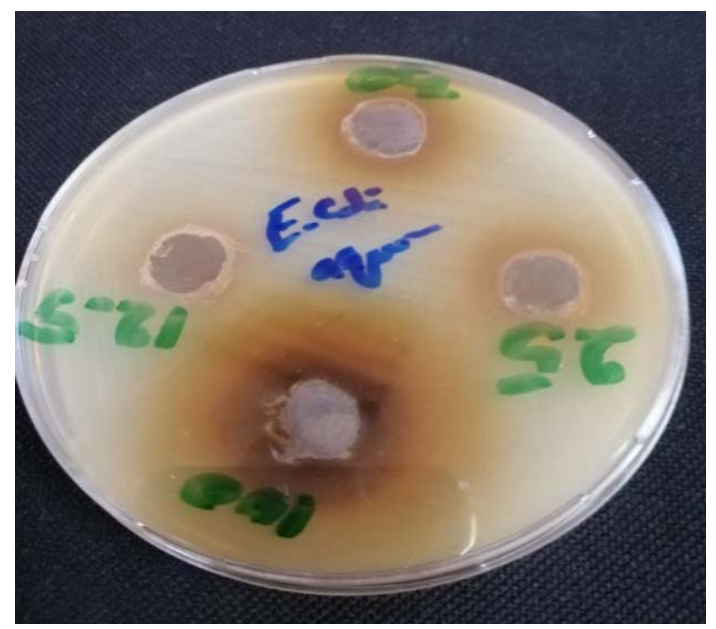

(D)

Figure (9): Antimicrobial activity of Acacia nilotica aqueous extract against: (1) Staphylococcus auras, (2) Pseudomonas aeruginosa, (3) Bacillus subtilus and (4) Escherichia coli. 


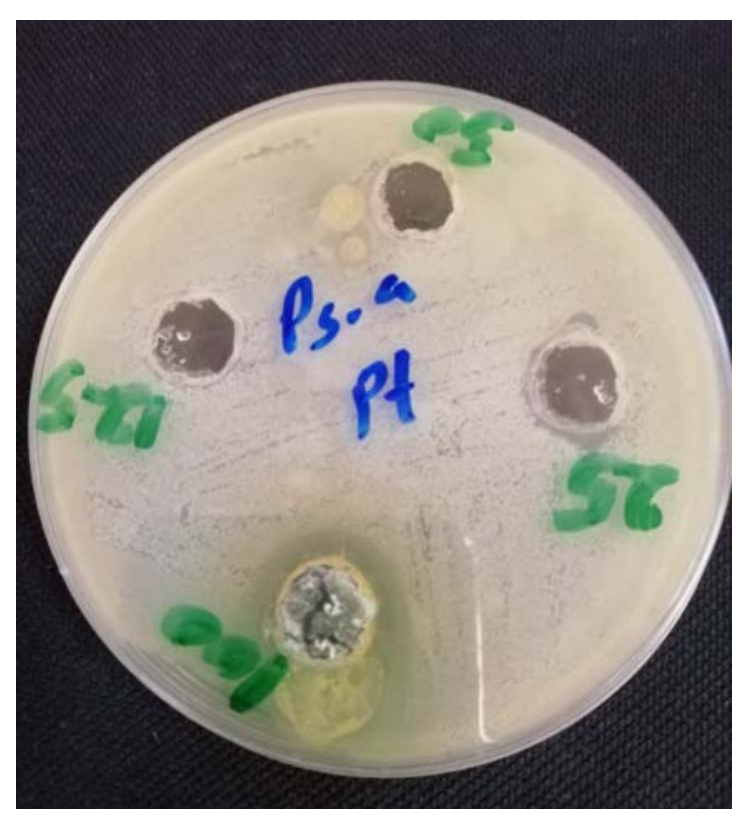

Figure (10): Antimicrobial activity of Acacia nioltica petroleum ether extract against Pseudomonas aeruginosa.

\section{Discussion:}

\subsection{Acacia nilotica fruits cover extracts properties and yield:}

Four solvents (distilled water, absolute ethanol, chloroform, and petroleum-ether) were used in successive extractable method; methanol solvent gave higher extractability than those obtain from petroleum-ether, chloroform and distilled water. In case of methanol and distill water the consistency of extractable material seem to be dark brown gamey, with differences in yield, and petroleum-ether and chloroform seem to be green powder with differences in yield. Petroleum-ether and chloroform are lower extractability than other solvents. Variations were observed in the colors of extracts may be reflection to type of solvent ingredients of plant.

\subsection{Phytochemical screening of Acacia nilotica:}

Phytochemical screening of chemical constituents Acacia nilotica fruits cover extracts, were found that all contain glycosides, flavonoids and terpenoids. The tannins were present in methanol and aqueous extracts, which also present in methanol extract; in addition Saponin was found in petroleum ether and methanol. (Table 3; Figure 2-7) All these compounds can act as natural anticancer agent.[15, 16]

The extracts of methanol results disagree with Rupal et al and Rwarinda et al; [17, 18] This difference may be due to the condition of experiment or well as difference in methodology of extraction and in variation(s) of secondary metabolites. 


\subsection{Antimicrobial activity of Acacia Nilotica:}

The methanol showed high activity at all concentration $(100 \%, 50 \%, 25 \%, 12 \%)$, against Staphylococcus aurous (22, 19, 18, 15), respectively as well as for Pseudomonas aeruginosa $(23,21,18,16)$, also for Bacillus subtilis $(24,22,20,17)$, and showed low activity against E. coli $(21,17,15$, ND); Petroleum ether was showed low activity at one concentration (100\%) on one organism Pseudomonas aeruginosa (17). Interestingly, chloroform has no inhibition zone against all tested microorganisms, while distilled water extract showed high activity against Pseudomonas aeruginosa (28, 26, 25, 22), and showed low activity against staphylococcus aureus (22, 20, 18, ND), also against Bacillus subtilis (25, 18, 16, ND), as well as for E. coli (20, 18, 14, ND) mm respectively.(Table 4; Figure 8-10)

This compared with assay reported by Hiba et al;[19] methanol extract of acacia nioltica fruit cover was found effective against all tested Gram negative and Gram positive bacteria with various inhibition zone (range between 32-16 mm). Aqueous extract of acacia nioltica fruit cover was moderately active against both Gram positive and gram negative bacteria inhibition zone (range between 28-14 mm).

In conclude, the two solvents methanol and distilled water has higher extractability than other solvents; The safety of medical plants is not complete of most them the usage of these plant without specific does subjected the people for other threats, therefore, More research needed on this plant Acacia nioltica from different habitats to specify the active component that makes inhibition for growth of microorganisms and may leads to play an important role in drug development programs in the pharmaceutical industries.

\section{Conclusion:}

Antimicrobial is resistance is reported to be on the increase due to the gene mutation of disease pathogens. Acacia nilotica was chosen for this study because of their reputation in folklore medicine as antimicrobial agents and used many part in many diseases.

Phytochemical screening was carried out and lead to presence of some secondary metabolites; the plant was showed to contain Flavonoids, Terpenoids, Glycosides, Saponin, Alkaloid and Tannin. The crude extracts were subjected to antimicrobial assays using well diffusion method and the inhibition zone was measured in $\mathrm{mm}$. The methanol and aqueous extracts gave good results against bacterial species were used, while Chloroform showed absence of inhibition zone against four bacterial species which were used.

\section{Acknowledgement:}

The authors acknowledge the Deanship of Scientific Research at University of Bahri for the supportive cooperation. 


\section{Data Availability:}

All data underlying the results are available as part of the article and no additional source data are required.

\section{References:}

[1] J. Fernandez, F. Bert, and M. H. Nicolas-Chanoine, "The challenges of multidrug-resistance in hepatology," J Hepatol, vol. 65, pp. 1043-1054, Nov 2016.

[2] T. Sen and S. K. Samanta, "Medicinal plants, human health and biodiversity: a broad review," Adv Biochem Eng Biotechnol, vol. 147, pp. 59-110, 2015.

[3] A. E. Mohammed, A. Al-Qahtani, A. Al-Mutairi, B. Al-Shamri, and K. F. Aabed, "Antibacterial and Cytotoxic Potential of Biosynthesized Silver Nanoparticles by Some Plant Extracts," Nanomaterials (Basel), vol. 8, May 302018.

[4] S. Massey, W. MacNaughtan, H. E. L. Williams, B. Wolf, and M. S. Iqbal, "A structural study of Acacia nilotica and Acacia modesta gums," Carbohydr Polym, vol. 175, pp. 207-215, Nov 12017.

[5] M. Maldini, P. Montoro, A. I. Hamed, U. A. Mahalel, W. Oleszek, A. Stochmal, et al., "Strong antioxidant phenolics from Acacia nilotica: profiling by ESI-MS and qualitative-quantitative determination by LC-ESI-MS," J Pharm Biomed Anal, vol. 56, pp. 228-39, Sep 102011.

[6] P. R. Bhushette and U. S. Annapure, "Comparative study of Acacia nilotica exudate gum and acacia gum," Int J Biol Macromol, vol. 102, pp. 266-271, Sep 2017.

[7] R. Singh, B. Singh, S. Singh, N. Kumar, S. Kumar, and S. Arora, "Anti-free radical activities of kaempferol isolated from Acacia nilotica (L.) Willd. Ex. Del," Toxicol In Vitro, vol. 22, pp. 1965-70, Dec 2008.

[8] T. N. Rao, Riyazuddin, P. Babji, N. Ahmad, R. A. Khan, I. Hassan, et al., "Green synthesis and structural classification of Acacia nilotica mediated-silver doped titanium oxide (Ag/TiO2) spherical nanoparticles: Assessment of its antimicrobial and anticancer activity," Saudi J Biol Sci, vol. 26, pp. 1385-1391, Nov 2019.

[9] M. J. Balunas and A. D. Kinghorn, "Drug discovery from medicinal plants," Life Sci, vol. 78, pp. 431-41, Dec 222005.

[10] S. S. Handa, S. Khanuja, G. Longo, and D. D. Rakesh, "Extraction technologies for medicinal and aromatic plants," International centre for science and high technology, pp. 21-25, 01/01 2008.

[11] N. R. Farnsworth, O. Akerele, A. S. Bingel, D. D. Soejarto, and Z. Guo, "Medicinal plants in therapy," Bull World Health Organ, vol. 63, pp. 965-81, 1985.

[12] J. B. Harborne, "Phytochemical methods : a guide to modern techniques of plant analysis," 2nd ed. ed. London ;: Chapman and Hall, 1984.

[13] A. Sofowora, "Research on medicinal plants and traditional medicine in Africa," $J$ Altern Complement Med, vol. 2, pp. 365-72, Fall 1996. 
[14] I. R. Kubra, P. S. Murthy, and L. J. M. Rao, "In vitro Antifungal Activity of Dehydrozingerone and its Fungitoxic Properties," Journal of Food Science, vol. 78, pp. M64-M69, 2013.

[15] K. M. Sakthivel, N. Kannan, A. Angeline, and C. Guruvayoorappan, "Anticancer activity of Acacia nilotica (L.) Wild. Ex. Delile subsp. indica against Dalton's ascitic lymphoma induced solid and ascitic tumor model," Asian Pac J Cancer Prev, vol. 13, pp. 3989-95, 2012.

[16] M. M. Salem, F. H. Davidorf, and M. H. Abdel-Rahman, "In vitro anti-uveal melanoma activity of phenolic compounds from the Egyptian medicinal plant Acacia nilotica," Fitoterapia, vol. 82, pp. 1279-84, Dec 2011.

[17] R. Singh and R. Thakur, "Phytochemical analysis and antibacterial activity of Acacia nilotica (L.) leaves against pathogenic bacteria," International Journal of Green Pharmacy, vol. 10, pp. 104-110, 04/28 2016.

[18] R. U. Angelo, "Efficacy of Acacia nilotica extracts towards microbicidal activity against pathogens," Int J Curr Microbiol Appl Sci, vol. 4, pp. 33-42, 2015.

[19] H. M. W. a. R. T. A. Sir., "Antimicrobial Activity of Acacia nilotica (Qaradh) Extract on Bacterial Species causing Wound Infections.," African Journal of Medical Sciences, vol. vol 2.5, 2017. 